Krzysztof Skowron ${ }^{1}$, Justyna Bauza-Kaszewska², Agnieszka Kaczmarek¹, Anna Budzyńska ${ }^{1}$, Joanna Kwiecińska-Piróg ${ }^{1}$, Adrian Reśliński ${ }^{3}$, Eugenia Gospodarek-Komkowska ${ }^{1}$

${ }^{1}$ Department of Microbiology, Nicolaus Copernicus University in Torun, Ludwik Rydygier Collegium Medicum in Bydgoszcz, Poland

2Department of Microbiology and Food Technology, University of Technology and Life Sciences, Bydgoszcz, Poland

${ }^{3}$ Clinic of Transplantology and General Surgery, Department of General Surgery and Transplantology, Nicolaus Copernicus University

in Torun, Ludwik Rydygier Collegium Medicum in Bydgoszcz, Poland

\title{
Inactivation of Clostridium sporogenes and Geobacillus stearothermophilus spores with the use of microwave and steam sterilizers and microwave oven
}

\author{
Corresponding author: \\ Krzysztof Skowron, PhD. Eng. \\ Department of Microbiology, \\ Nicolaus Copernicus University \\ in Torun, \\ Collegium Medicum in Bydgoszcz \\ 9 Sklodowskiej-Curie St. \\ 85-094 Bydgoszcz, Poland \\ Phone: +48525853838 \\ Fax: +48525854047 \\ E-mail: skowron238@wp.p
}

Medical Research Journal 2016; Volume 1, Number 1, 15-22 10.5603/MRJ.2016.0003 Copyright (C) 2016 Via Medica ISSN 2451-2591

\begin{abstract}
Introduction. Equipment for sterilization used in medical laboratories must be absolutely effective in eliminating microorganisms and their spores. It often directly influences human health, even life. The aim of the study was to compare the effectiveness of sterilization using the steam sterilizer ASV E, microwave sterilizer EnbioJet ML1, microwave sterilizer for baby bottles and breast pumps AVENT and microwave oven. Materials and methods. Evaluation of the effectiveness of sterilization with the use of selected devices based on pressure-thermal and microwave-thermal methods was conducted, on the basis of elimination of G. stearothermophilus PCM 2104 and C. sporogenes IW 1306 spores.

Results. After using the steam sterilizer, $100 \%$ inactivation of spores of both species was noted. In the case of EnbioJet ML1 sterilizer, in the test containing $10^{6} \mathrm{CFU} \times \mathrm{cm}^{-3} \mathrm{G}$. stearothermophilus spores, $1.63 \times 10^{1} \mathrm{CFU} \times \mathrm{cm}^{-3}$ survived. The baby bottles sterilizer proved less effective. While the microwave, in the case of tests with the highest spore content, provided their inactivation only at the level of more than $70.0 \%$. The steam sterilizer and EnbioJet ML1 sterilizer were the most effective, whereas the latter ensured a very short time of high temperature effect, which has a favorable impact on the properties of sterilized products, for example compounds decomposing in high temperature.

Conclusion. Results of own, as well as other authors' studies allow to confirm the large potential in the scope of using microwave radiation for the sterilization and disinfection of materials of various sensitivity to temperature.
\end{abstract}

Key words: spores, Clostridium sporogenes, Geobacillus stearothermophilus, sterilization, microwave radiation

Med Res J 2016; 1 (1): 15-22

\section{Introduction}

Equipment for sterilization used in medical, industrial or research laboratories must be characterized by an absolute effectiveness in eliminating microorganisms and their spores. It often directly influences human health, even life, and in the case of scientific facilities it is crucial for the reliability of the conducted research.

Commonly used methods of sterilization are based primarily on high temperature, often in combination with appropriately modified pressure. With the mainte- nance of parameters specified for a given technological process and adequately frequent control, they are able to provide normatively specified requirements for sterilization. Simultaneously, new methods are being developed, the aim of which is to e.g. shorten the sterilization time, simplify technology or lower the costs of its use while maintaining a similar degree of effectiveness. For destruction of germs they use vaporized $\mathrm{H}_{2} \mathrm{O}_{2}$ and gas plasma $\mathrm{H}_{2} \mathrm{O}_{2}$, ozone, disinfectants of new generation or antibiotic substances of natural origin [1-4]. 
Microwave radiation shows high efficiency in the scope of inactivation of bacteria [5-8]. The benefits connected with the possibility of its use result mainly from the short time of high temperature effect, which, together with the optimization of the process conditions, allows to minimize unfavorable changes in structure and quality occurring in the sterilized material.

In this work two strains of spore-forming bacteria Clostridium sporogenes and Geobacillus stearothermophilus were subjected to the action of microwave radiation. These bacilli, regarded as non-pathogenic, may contribute to food products going bad [9-11]. However, their particular importance results from the fact that considering the high temperature resistance of spores, G. stearothermophilus is used as an indicator of efficiency of the sterilization process, especially conducted in an autoclave, and $C$. sporogenes can be used in research instead of pathogenic species Clostridium botulinum [12-14].

The aim of the study was to compare the efficiency of sterilization carried out using the microwave sterilizer EnbioJet ML1, steam sterilizer ASV E, microwave sterilizer AVENT for baby bottles and breast pumps, and microwave oven Samsung GW73B, determined on the basis of the inactivation of spores $G$. stearothermophilus and C. sporogenes.

\section{Materials and methods}

Evaluation of the effectiveness of sterilization with the use of selected devices based on pressure-thermal and microwave-thermal methods was conducted on the basis of elimination of $G$. stearothermophilus PCM 2104 and $C$ sporogenes IW 1306 spores. Both reference strains came from the Polish Collection of Microorganisms of L. Hirszfeld Institute of Immunology and Experimental Therapy in Wroctaw. The control variant was the steam sterilizer ASV E, and the tested devices were: microwave sterilizer EnbioJet ML1 (Enbio Technology Sp. z o.o., Poland), microwave sterilizer AVENT for baby bottles and breast pumps and microwave oven Samsung GW73B with the capacity of 1100 W with Erlenmeyer flask inside, filled with suspension of spores in sterile deionized water. The experiment was carried out in 3 independent repetitions for each of the devices.

\section{Preparation of suspension of Clostridium sporogenes spores}

Freeze-dried reference strain of $C$. sporogenes IW 1306 was inoculated on Tryptone Soya Agar (TSA, Merck Millipore, Germany) and incubated for 72 hours in the temperature of $37^{\circ} \mathrm{C}$ in anaerobic conditions using Anaerobic System sachets (Oxoid, United Kingdom). After this period, bacterial suspensions with the density
2 on the McFarland scale were prepared in $5 \mathrm{~mL}$ of Brain Heart Infusion Broth (BHI, Merck Millipore) and covered with sterile liquid paraffin to achieve a layer with the thickness of $1 \mathrm{~cm}$. Then the suspensions were placed in the temperature of $4^{\circ} \mathrm{C}$ for 28 days. After this time, $0.5 \mathrm{~mL}$ of $C$. sporogenes culture was added to $10 \mathrm{~mL}$ of Fluid Thioglycollate broth (FTG, Sigma-Aldrich, Germany) and incubated for 24 hours in the temperature of $37^{\circ} \mathrm{C}$ in anaerobic conditions obtained by using Anaerogen Gas generating system (OXOID, UK). From the obtained cultures $0.5 \mathrm{~mL}$ was transferred to $10 \mathrm{~mL}$ of Duncan-Strong broth ( $4 \mathrm{~g}$ of yeast extract, $15 \mathrm{~g}$ of proteose peptone, $4 \mathrm{~g}$ of soluble starch, $1 \mathrm{~g}$ sodium thioglycollate and $10 \mathrm{~g}$ of $\mathrm{Na}_{2} \mathrm{HPO}_{4} \cdot 7 \mathrm{H}_{2} \mathrm{O}$ dissolved in $1000 \mathrm{~mL}$ of distilled water [15] and incubated in anaerobic conditions for 7 days in the temperature of $37^{\circ} \mathrm{C}$. Ready cultures were heated in the temperature of $80^{\circ} \mathrm{C}$ for 20 minutes in order to eliminate vegetative forms of $C$. sporogenes, and then rapidly cooled to $20^{\circ} \mathrm{C}$. After cooling, the contents of the test tubes were poured into the Falcons tubes of centrifuge (Eppendorf 5810R, Germany), centrifuged at the speed of $20,160 \times g$ for 10 minutes and the supernatant was removed. Sediment of spores was twice washed with sterile distilled water, and the supernatant was poured out and suspended in sterile distilled water.

The prepared suspension was evaluated in terms of $C$. sporogenes spores viable for germination. To this end, a series of decimal dilutions of the tested suspension in sterile distilled water was carried out and inoculated using the method of deep inoculation on solidified (addition of $9 \mathrm{~g}$ of agar for $500 \mathrm{~mL}$ of broth) substrate Differential Reinforced Clostridial Broth (DRCM, Merck Millipore). After 72 hours of incubation in the temperature of $37^{\circ} \mathrm{C}$ in anaerobic conditions, the grown black colonies were counted. The suspension with concentration of spores viable for germination fixed at the level of $10^{8} \mathrm{CFU} \times \mathrm{cm}^{-3}$ was stored at $4^{\circ} \mathrm{C}$.

\section{Preparation of suspension of Geobacillus stearothermophilus spores}

Freeze-dried reference strain of G. stearothermophilus PCM 2104 was cultured on TSA substrate and incubated for 24 hours in the temperature of $60^{\circ} \mathrm{C}$. Then, on a sporulation substrate [16], containing in $1 \mathrm{dm}^{3}: 30 \mathrm{~g}$ of TSB, $0.125 \mathrm{~g}$ of $\mathrm{CaCl}_{2}, 0.15 \mathrm{~g}$ of $\mathrm{MnSO}_{4}$, $0.155 \mathrm{~g}$ of $\mathrm{FeSO}_{4}$ and $0.55 \mathrm{~g}$ of $\mathrm{MgCl}_{2}$, suspensions with the density 2 on the McFarland scale were prepared and incubated in the temperature of $60^{\circ} \mathrm{C}$ for 96 hours, with constant stirring of the culture. After the incubation, the cultures were heated in the temperature of $80^{\circ} \mathrm{C}$ for 30 minutes in order to eliminate vegetative forms of $G$. stearothermophilus, and then rapidly cooled to $20^{\circ} \mathrm{C}$. After cooling, the contents of the test tubes were poured into the Falcons centrifuge tubes (Eppendorf 
5810R) and centrifuged at the speed of $20,160 \times \mathrm{g}$ for 10 minutes, removing the supernatant. Sediment of spores was washed three times with sterile distilled water, the supernatant was poured out and suspended in sterile distilled water.

The prepared suspension was evaluated in terms of $G$. stearothermophilus spores viable for germination. To this end, a series of decimal dilutions of the tested suspension in $1 \%$ buffered peptone water (Merck Millipore) was carried out and inoculated on TSA substrate. After 24 hours of incubation in the temperature of $60^{\circ} \mathrm{C}$, the grown colonies were counted. The suspension with concentration of spores viable for germination fixed at the level of $10^{6} \mathrm{CFU} \times \mathrm{cm}^{-3}$ was stored at $4^{\circ} \mathrm{C}$.

\section{Preparation of standard suspension tests and assessment of the efficiency of sterilization}

In order to conduct an assessment of the sterilization efficiency of the chosen devices, on the basis of initial suspensions of C. sporogenes IW 1306 and G. stearothermophilus PCM 2104, three independent rows of decimal dilutions in sterile distilled water were prepared. For C. sporogenes those were dilutions containing $10^{8}$ to $10^{1} \mathrm{CFU} \times \mathrm{cm}^{-3}$, and for $\mathrm{G}$. stearothermophilus - from $10^{6}$ to $10^{1} \mathrm{CFU} \times \mathrm{cm}^{-3}$. Then, for each dilution in each of the three rows, the number of spores viable for germination was determined (positive control). After checking the initial concentration of spores, from each dilution $200 \mathrm{~mL}$ was poured out to 4 sterile flasks, filling them to the reference volume. Then one of the flasks from each dilution, from each of the three rows, was placed in a given sterilization device, therefore, obtaining 3 repetitions.

After sterilization, for each suspension test in each repetition a number of decimal dilutions was prepared. For $C$. sporogenes the dilutions were made in sterile distilled water, and then deep-inoculated, using DRCM substrate with the addition of agar, incubated for 72 hours in the temperature of $37^{\circ} \mathrm{C}$ in anaerobic conditions and the grown colonies were counted.

In the case of $G$. stearothermophilus, the dilutions prepared in $1 \%$ buffered peptone water were inoculated on TSA. The incubation was carried out for 24 hours in the temperature of $60^{\circ} \mathrm{C}$, and then the grown colonies were counted.

For both species of bacteria, the indicator of inactivation of spores for each of the tested devices was calculated using the equation [1]:

$$
I=\frac{(A-B)}{A} \times 100 \%
$$

A - number of spores viable for germination in a given suspension test

B - number of spores viable for germination after sterilization

\section{Sterilization in individual tested devices}

The basic sterilization conditions for each device are presented in Table 1.

In the conducted experiment, sterilization in the steam sterilizer ASV E was used as the control variant. When testing the efficiency of this device, all flasks containing suspension tests with $C$. sporogenes and G. stearothermophilus spores were placed in a working chamber in a two-level wire basket. The parameters of the process were as follows: temperature $121^{\circ} \mathrm{C}$, sterilization time 21 minutes, pressure 1.52 bar (Tab. 1).

In order to assess the sterilization efficiency of the microwave sterilizer EnbioJet ML1, single flasks containing prepared suspension tests of specified concentration of spores were placed in a working chamber, and the sterilization process was carried out for 7 minutes, in accordance with the manufacturer's recommendations (Tab. 1).

In the case of the microwave sterilizer AVENT for baby bottles and breast pumps, $200 \mathrm{~mL}$ of sterile distilled water was poured inside the device, and 6 flasks with suspension tests were simultaneously put in. Then, the device was closed tight, and, in accordance with the manufacturer's recommendations, put inside the microwave oven Samsung GW73B with the capacity of $1100 \mathrm{~W}$ (radiation power $750 \mathrm{~W}$ ) and microwave radiation frequency of $2.45 \mathrm{GHz}$ for 2 minutes (effective exposure time - 114 seconds). After completion of the process, the temperature of the flasks contents was measured with a sterile thermometer, recording on average $101.3^{\circ} \mathrm{C}$ (Tab. 1).

In order to assess the sterilization efficiency of the microwave oven Samsung GW73B flasks containing suspension tests of various concentration of spores were placed directly on the rotating tray of the microwave oven with the capacity of $1100 \mathrm{~W}$ (radiation power $750 \mathrm{~W}$ ) and microwave radiation frequency of $2.45 \mathrm{GHz}$ for 2 minutes (effective exposure time - 114 seconds). After completing the process, the temperature of the flasks contents amounted to an average of $90.2^{\circ} \mathrm{C}$ (Tab. 1).

\section{Results}

It was concluded that the tested devices, except the microwave oven, provided a satisfactory disinfection level, exceeding 99.0\%. However, sterilization, consistent with the definition of the process, can only be noted in the case of the steam sterilizer ASV E, which independently of the initial number of spores in the suspension test, guaranteed $100.0 \%$ level of their inactivation (Tab. 2 and Tab. 3).

Microwave sterilizer EnbioJet ML1 ensured the complete inactivation of $C$. sporogenes spores at their 
Table 1. Sterilization conditions

\begin{tabular}{lllll}
\hline $\begin{array}{l}\text { Sterilization } \\
\text { conditions }\end{array}$ & $\begin{array}{l}\text { Steam sterilizer } \\
\text { ASV E }\end{array}$ & EnbioJet ML1 & $\begin{array}{l}\text { Microwave sterilizer } \\
\text { AVENT for bottles }\end{array}$ & $\begin{array}{l}\text { Microwave oven } \\
\text { Samsung GW73B }\end{array}$ \\
\hline $\begin{array}{l}\text { Temperature }\left[{ }^{\circ} \mathrm{C}\right] \\
\text { Time [minutes] }\end{array}$ & 121 & 135 & 101.3 & 90.2 \\
& 21 & $\begin{array}{l}7 \\
\text { (effective sterilization }\end{array}$ & 2 & 2 \\
$\begin{array}{l}\text { Pressure [bar] } \\
\text { - } 1 \text { minute) }\end{array}$ & 1.52 & 3.60 & - & - \\
$\begin{array}{l}\text { Microwave radiation } \\
\text { frequency [GHz] }\end{array}$ & - & 2.45 & 2.45 & 2.45 \\
\hline
\end{tabular}

initial number set within the limits from $3.90 \times 10^{1}$ to $3.04 \times 10^{8} \mathrm{CFU} \times \mathrm{cm}^{-3}$ (Tab. 2). It was slightly worse in the case of the efficiency of elimination of G. stearothermophilus spores viable for germination. Full inactivation of spores of this germ was noted in the case of their initial number within the limits from $2.73 \times 10^{1}$ to $2.37 \times 10^{5} \mathrm{CFU} \times \mathrm{cm}^{-3}$. And for the suspension test containing $5.00 \times 10^{6} \mathrm{CFU} \times \mathrm{cm}^{-3}$, after completing the process, $1.63 \times 10^{1}$ spores of $G$. stearothermophilus viable for germination were retrieved, so the inactivation indicator amounted to $99.99 \%$ (Tab. 3).

In the case of the steam sterilizer ASV E, the indicator of inactivation of spores of both bacteria species in each case amounted to $100.0 \%$ (Tab. 2 and Tab. 3).

The microwave sterilizer AVENT for baby bottles and breast pumps, with similar in principle operation to the EnbioJet ML1 device, ensured $100.0 \%$ inactivation of $C$. sporogenes spores, at their initial number from $3.90 \times 10^{1}$ to $5.70 \times 10^{5} \mathrm{CFU} \times \mathrm{cm}^{-3}$ (Tab. 2), and G. stearothermophilus spores at the concentration within the limits from $2.73 \times 10^{1}$ to $3.21 \times 10^{5} \mathrm{CFU} \times \mathrm{cm}^{-3}$ (Tab. 3). In the case of suspension tests containing more spores, the inactivation indicator for the discussed device amounted to $99.99 \%$ in the case of C. sporogenes (Tab. 2) and from $99.91 \%$ to $99.99 \%$, depending on the initial concentration of spores, for $G$. stearothermophilus (Tab. 3).

The lowest disinfection efficiency was noted in the case of the microwave oven. Full inactivation of $C$. sporogenes spores was noted for this device at their initial number in the test from $3.90 \times 10^{1}$ to $2.67 \times 10^{2} \mathrm{CFU} \times \mathrm{cm}^{-3}$ (Tab. 2), and G. stearothermophilus spores only at the lowest tested concentration (Tab. 3). Exceeding the level of $90 \%$ inactivation, ensuring a drop in the number of tested spores by one logarithmic unit, was noted for the number of spores in the test lower than $3.27 \times 10^{4} \mathrm{CFU} \times \mathrm{cm}^{-3}$ for C. sporogenes (Tab. 2) and $6.17 \times 10^{3} \mathrm{CFU} \times \mathrm{cm}^{-3}$ for G. stearothermophilus (Tab. 3). In the case of tests containing the highest tested number of spores, amounting to $3.04 \times 10^{8} \mathrm{CFU} \times \mathrm{cm}^{-3}$ for $C$. sporogenes, and $5.00 \times 10^{6} \mathrm{CFU} \times \mathrm{cm}^{-3}$ for $\mathrm{G}$. stearothermophilus, the value of the inactivation indicator was determined at the level of $70.43 \%$ and $78.93 \%$ (Tab. 2 and Tab. 3). This resulted in retrieving spores of both species respectively in the number of $9.00 \times 10^{7} \mathrm{CFU} \times \mathrm{cm}^{-3}$ and $1.05 \times 10^{6} \mathrm{CFU} \times \mathrm{cm}^{-3}$ (Tab. 2 and Tab. 3).

\section{Discussion}

The work compares the effectiveness of sterilization using the microwave sterilizer EnbioJet ML1, microwave sterilizer AVENT for baby bottles and microwave oven Samsung GW73B in relation to the steam sterilizer ASV E. It was concluded that the most effective were the steam sterilizer and the sterilizer EnbioJet ML1, whereas the latter ensured a very short time of high temperature effect, which has a favorable impact on the properties of sterilized products.

Efficient inactivation of spores is one of the methods of assessing the correctness of operation of sterilization devices. To achieve this, species of high resistance to temperature are used as biological indicators. One of them is G. stearothermophilus, for which the value of $D_{121^{\circ} \mathrm{C}}$, depending on the composition of the growth substrate, varies from 1.3 to 5.4 minutes [10]. C. sporogenes is characterized by a lower resistance to high temperature $\left(D_{121^{\circ} \mathrm{C}} 0.92-1.5\right.$ minutes $)$, but elimination of its spores also guarantees the destruction of $C$. botulinum spores, with thermal sensitivity a few times higher $[17,18]$. In own studies, using steam sterilizer ASV E led to $100 \%$ inactivation of spores of both species, regardless of their initial number in the suspension tests. However, spores of $C$. sporogenes showed higher than $G$. stearothermophilus sensitivity to microwave radiation of both devices. This difference is explained by the different heat-sensitivity of C. sporogenes and G. stearothermophilus, which was mentioned above. 
응

$\underline{2}$

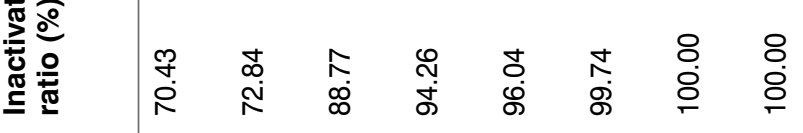

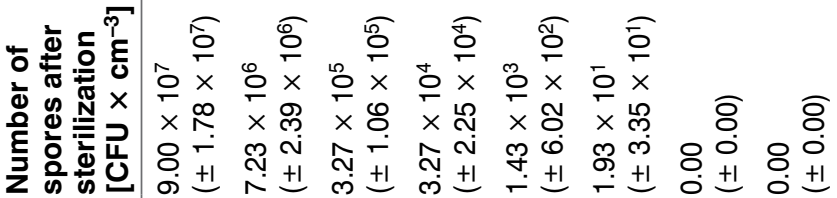

to

ธำ

Ð

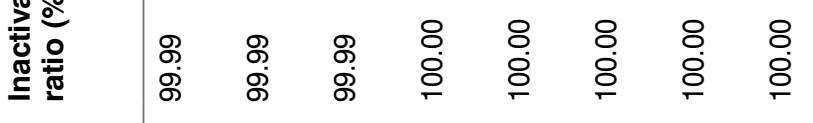

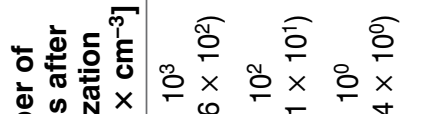

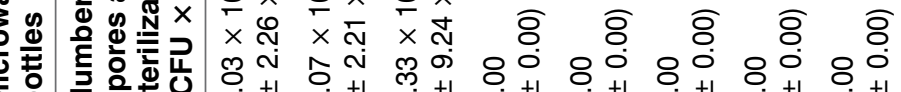

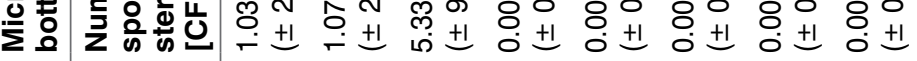

흘

这

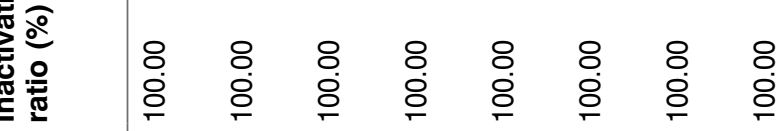

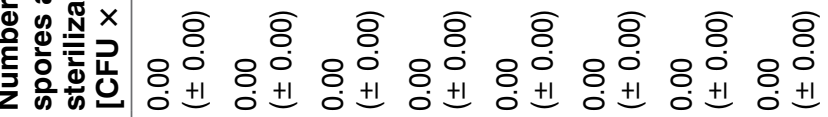

б

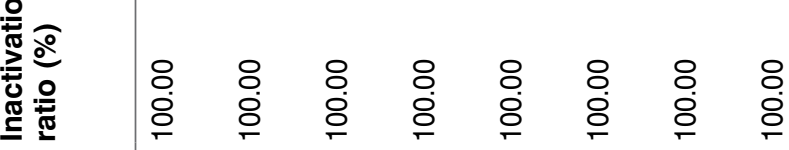

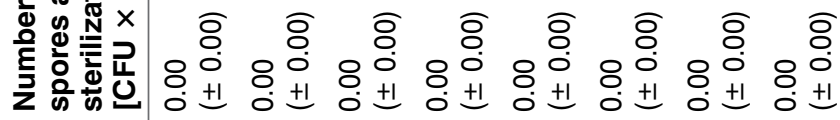

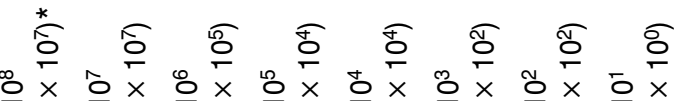

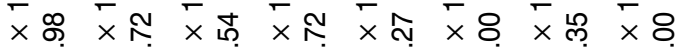

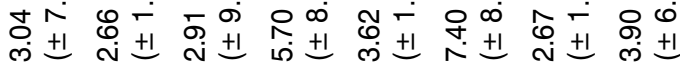




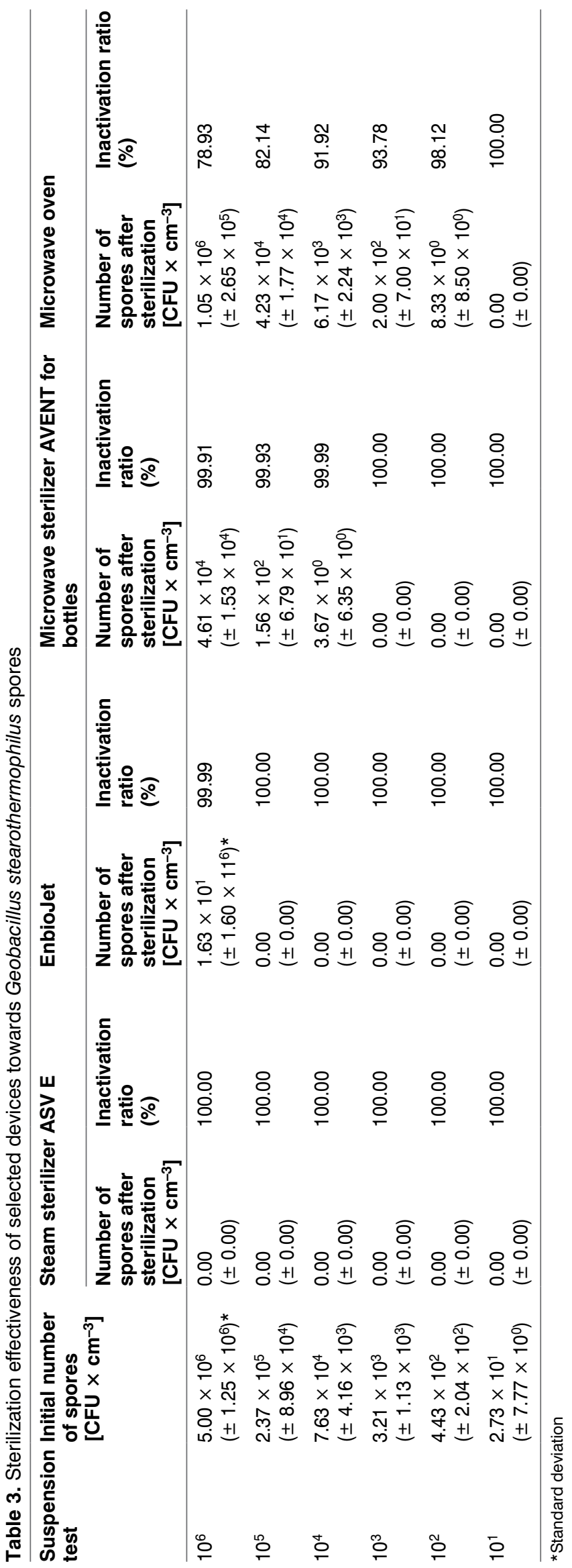


Destruction of vegetative bacteria cells and their spores under the influence of microwaves results mainly from high temperature and the so-called non-thermal effect, questioned by some researchers [19]. Lethal changes in cell structures of the radiated germs involve cell wall, DNA and cytoplasm proteins [20]. Microscope observations proved that the mechanism of destroying both bacterial vegetative cells and spores by microwaves is different than in the case of conventional heating. In the suspension of Bacillus licheniformis spores subjected to microwaves with the capacity of $2 \mathrm{~kW}$, numerous proteins and DNA were noted, which got outside through destroyed spore coats. The activity of the protein CotA located in the spore capsule, which did not change its properties during classic boiling, was completely inhibited [21].

The lethal influence of microwaves on bacterial spores, regardless of the mechanism of this influence, was confirmed many times. In the research of Laguerre et al. [22], inactivation of $G$. stearothermophilus spores reaching 1 log took place, depending on the used radiation power, within 50 to 150 seconds. 8-minute action of microwaves caused the destruction of $100 \%$ of C. sporogenes and G. stearothermophilus spores [23].

The efficiency of sterilization with the use of microwaves results mainly from the purpose of the used device, associated radiation power which can be ensured and time of action. In own studies, the microwave oven showed relatively low efficiency in the scope of elimination of spores. The inactivation indicator of the suspension of C. sporogenes spores with the density of $10^{8} \mathrm{CFU} \times \mathrm{cm}^{-3}$ subjected to its action, amounted to $70.4 \%$, which probably resulted from the low temperature generated inside this device (Tab. 2). According to Woo et al. [24], 5 log reduction of number of $B$. subtilis and $E$. coli cells subjected to microwaves took place fastest until reaching the temperature of $60^{\circ} \mathrm{C}$. An increase above this value influenced the tested microbes in a less significant way.

High hopes connected with broadening the scope of application of microwave radiation for sterilization purposes concern possibilities of integrating their action with the influence of higher pressure [25]. The result of such combination is the increase of temperature guaranteeing the effective elimination even of the germs of high resistance to temperature. Using high pressure (700-900 MPa) in the temperature scope of $80-100^{\circ} \mathrm{C}$ accelerated the process of destroying $C$. sporogenes spores introduced to fish pulp and milk. However, similar dependencies were not observed after raising the temperature above the value of $100^{\circ} \mathrm{C}$. The efficiency of used combination of physical factors in the scope of elimination of spores was dependent on the type of substance to which it was introduced and the tested strain [26, 27]. Patazca et al. [28] claim that the combination of elevated pressure and high temperature enables faster inactivation of $G$. stearothermophilus spores. Along with the increase of temperature from $92^{\circ} \mathrm{C}$ to $111^{\circ} \mathrm{C}$, their resistance to increased pressure decreased $\left(z_{p}\right)$ from the value of $352 \mathrm{MPa}$ to $216 \mathrm{MPa}$.

Combined action of pressure and temperature resulting from the microwave radiation used in the microwave sterilizer EnbioJet ML1 resulted in $100 \%$ inactivation of $C$. sporogenes spores - similarly as in the steam sterilizer ASV E. Its efficiency was slightly lower in the case of the suspension of $G$. stearothermophilus spores of the highest of tested densities $-10^{6} \mathrm{CFU} \times \mathrm{cm}^{-3}$. Assuming that the number of high temperature resistant spores in the sterilized materials rarely reaches such high values, the obtained results suggest that the efficiency of the microwave sterilizer EnbioJet ML1 may fulfill the requirements of microbiology laboratories. An additional, but significant benefit of this device, giving it advantage over a traditional autoclave, is the short time of the sterilization process. It is, along with lowering the temperature of the process, one of the main technological trends concerning the construction and functioning of sterilization devices [3, 29].

Constructing specialized devices using the speed and efficiency of microwaves, sterilized through them thermostable medical instruments and aprons. Results of many experiments also prove that after optimizing the parameters accompanying this process it is possible to use this method also for more sensitive materials. According to Kothari et al. [25], treating substrates for bacteria and fungi cultures with microwaves resulted in stronger growth of these microorganisms. It resulted from the shorter, in comparison with autoclave, time of heating the substrate, which enables a better retention of nutrients. On the other hand, Laguerre et al. [22], when testing the influence of microwaves on $G$. stearothermophilus spores in milk, determined the so-called "optimal zone" of the sterilization process. This concept defines the power and time of action of radiation, ensuring a satisfactory level of destruction of spores at the lowest possible loss of nutrients and limiting to the minimum the number of harmful side compounds generated in thermal processes (Maillard reaction products).

\section{Conclusions}

1. Results of own, as well as other authors' studies, allow to confirm the large potential in the scope of using microwave radiation for the sterilization and disinfection of materials of various sensitivity to temperature.

2. Particularly, the sterilizer EnbioJet ML1 ensured efficiency very similar to the standard steam sterilizer.

3. The fast effect of microwaves, enabling to shorten the time of high temperature effect, surely constitutes 
an important stimulus to conduct further research in this field. However, we should remember about the inferiority of temperature unevenness, which is a serious problem of microwave sterilization.

\section{References}

1. Akitsu T, Ohkawa H, Tsuji M, Kimura H, Kogoma M. Plasma sterilization using glow discharge at atmospheric pressure. Surf Coat Techno 2005; 193: 29-34.

2. Reich MS, Akkus O. Sporicidal efficacy of genipin: a potential theoretical alternative for biomaterial and tissue graft sterilization. Cell Tissue Bank 2013; 14: 381-393

3. Schneider PM. New technologies and trends in sterilization and disinfection. Am J Infect Control 2013; 41: 81-86.

4. Viedma PM, Abriouel H, Omar NB, López RL, Gálvez A. Effect of enterocin EJ97 against Geobacillus stearothermophilus vegetative cells and endospores in canned foods and beverages. Europ Food Res Technol 2010; 230: 513-519.

5. Bauza-Kaszewska J, Skowron K, Paluszak Z, Dobrzański Z, Śrutek M Effect of microwave radiation on microorganisms in fish meals. Ann Anim Sci 2014; 14: 623-636.

6. Celandroni $\mathrm{F}$, Longo I, Tosoratti $\mathrm{N}$ et al. Effect of microwave radiation on Bacillus subtilis spores. J Appl Microbiol 2004; 97: 1220-1227.

7. Shamis Y, Taube A, Shramkov Y, Mitik-Dineva N, Vu B, Ivanova, EP Development of a microwave treatment technique for bacterial decontamination of raw meat. Int J Food Eng 2008; 4: 359-371.

8. Valsechi AO, Horii J, Angelis D. The effect of microwaves on microorganisms. Arquivos do Instituto Biológico, Sao Paulo 2004; 71: 399-404.

9. Lücking G, Stoeckel M, Atamer Z, Hinrichs J, Ehling-Schulz M Characterization of aerobic spore-forming bacteria associated with industrial dairy processing environments and product spoilage. Int. $J$ Food Microbiol 2013; 166: 270-279.

10. Postollec F, Mathot AG, Bernard M, Divanac'h ML, Pavan S, Sohier D. Tracking spore-forming bacteria in food: From natural biodiversity to selection by processes. Int J Food Microbiol 2012; 158: 1-8.

11. Rigaux C, André S, Albert I, Carlin, F. Quantitative assessment of the risk of microbial spoilage in foods. Prediction of non-stability at $55^{\circ} \mathrm{C}$ caused by Geobacillus stearothermophilus in canned green beans. Int J Food Microbiol 2014; 171: 119-128.

12. Brown JL, Tran-Dinh N, Chapman B. Clostridium sporogenes PA 3679 and its uses in the derivation of thermal processing schedules for low-acid shelf-stable foods and as a research model for proteolytic Clostridium botulinum. J Food Protect 2012; 75: 779-792.

13. Gao Yl, Ju XR, Jiang $\mathrm{HH}$. Analysis of reduction of Geobacillus stearothermophilus spores treated with high hydrostatic pressure and mild heat in milk buffer. J Biotechnol 2006; 125: 351-360.
14. Guizelini BP, Vandenberghe LPS, Sella SRBR, Soccol CR. Study of the influence of sporulation conditions on heat resistance of Geobacillus stearothermophilus used in the development of biological indicators for steam sterilization. Arch Microbiol 2012; 194: 991-999.

15. Duncan CL, Strong DH. Improved medium for sporulation of Clostridium perfringens. Appl Microbiol 1968; 16: 82-89.

16. Seale RB, Flint SH, McQuillan AJ, Bremer P.J. Recovery of spores from thermophilic dairy bacilli and effects of their surface characteristics on attachment to different surfaces. Appl Environ Microbiol 2008; 74: 731-737.

17. Brown KL. Control of bacterial spores. Brit Med Bull 2000; 56: 158-171.

18. Byun BY, Cho HY, Hwang $\mathrm{HJ}$ et al. Optimization and evaluation of heat-shock condition for spore enumeration being used in thermal-process verification: Differential responses of spores and vegetative cells of Clostridium sporogenes to heat shock. Food Sci Biotechnol 2011; 20: 751-757.

19. Gedikli S, Tabak O, Tomsuk O, Cabuk, A. Effect of microwaves on some gram negative and gram positive bacteria. J Appl Biol Sci 2008; 2: $67-71$.

20. Kim SY, Jo EK, Kim HJ, Bai K, Park JK. The effects of high-power microwaves on the ultrastructure of Bacillus subtilis. Lett Appl Microbiol 2008; 47: 35-40

21. Kim SY, Shin SJ, Song CH, Jo EK, Kim HJ, Park JK. Destruction of Bacillus licheniformis spores by microwave irradiation. J Appl Microbiol 2009; 106: 877-885

22. Laguerre JC, Pascale GW, Marier DM, Evelyne O, Lamia AA, Inès B.A. The impact of microwave heating of infant formula model on neo-formed contaminant formation, nutrient degradation and spore destruction. J Food Engl 2011; 107: 208-213

23. Vaid $A$, Bishop $A H$. The destruction by microwave radiation of bacterial endospores and amplification of the released DNA. J Appl Microbiol 1998; 85: 115-122.

24. Woo IS, Rhee IK, Park HD. Differential damage in bacterial cells by microwave radiation on the basis of cell wall structure. Appl Environ Microbiol 2000; 66: 2243-2247.

25. Kothari V, Patadia M, Trivedi N. Microwave sterilized media supports better microbial growth than autoclaved media. Res Biotechnol 2011:2: 63-72.

26. Ramaswamy HS, Shao Y. High pressure destruction kinetics of Clostridium sporogenes spores in salmon slurry at elevated temperatures. Int J Food Prop 2012; 13: 1074-1091.

27. Shao Y, Ramaswamy HS. Clostridium sporogenes - ATCC 7955 spore destruction kinetics in milk under high pressure and elevated temperature treatment conditions. Food Bioprocess Technol 2011; 4: 458-468.

28. Patazca E, Koutchma T, Ramaswamy HS. Inactivation kinetics of Geobacillus stearothermophilus spores in water using high-pressure processing at elevated temperatures. J Food Sci 2006; 71: 110-116.

29. Kameda T, Ohkuma K, Sano N, Batbayar N, Terashima Y, Terada, K. Development of a compact induction-heated autoclave with a dramatically shortened sterilization cycle in orthodontic clinics. Orthod Waves 2014; 73: 55-60. 